\title{
METHODS FOR KINETIC ANALYSIS OF METHANE FERMENTATION IN HIGH SOLIDS BIOMASS DIGESTERS
}

\author{
Brian K. Richards, Robert J. Cummings, Thomas E. White* and William J. Jewell \\ Department of Agricultural and Biological Engineering, Riley-Robb Hall, Cornell University, Ithaca, \\ NY 14853-5701, U.S.A.
}

(Accepted 23 April 1991)

\begin{abstract}
Methods are presented for kinetic analysis of anacrobic biomass reactors. In some cases, assumptions implicit in kinetic analysis techniques developed for conventional dilute digestion modes are not applicable to systems operating at high rates and/or high solids concentrations. As a result, modified definitions are presented for CST digester retention tines and first order kinetic coefficients. Procedures are presented for converting biogas data to standard conditions. Two novel methods for quantifying mass removals, based on direct measurement of reactor mass losses and on biogas production, allow rapid determination of mass removal rates and detection of gas leakage. The use of a per unit mass basis for reporting concentrations and kinetics is recommended.
\end{abstract}

Keywords-Kinetic analysis, anaerobic digestion, methane, biogas, biomass, high solids digestion, anaerobic composting.

\section{INTRODUCTION}

Recent years have seen a significant amount of research focused on optimizing anaerobic fermentation of biomass (agricultural residues, energy crops, municipal solid waste) to produce methane. In order to optimize reactor methane production rates, digestion is often carried out at relatively high reactor solids contents, ranging from slurries operating at about $10 \%$ total solids 1,2 to "dry" high solids systems operating at over $30 \%$ TS.,4 However, methods used for describing the performance of these systems are often adopted from kinetic analysis techniques developed to describe anaerobic treatment of very dilute waste streams such as sewage sludge (1 to $5 \%$ TS). Because of the differences between dilute and higher solids systems, several assumptions implicit in these "conventional" techniques do not hold true.

Procedures presented here were developed during an extensive biomass conversion research project at Cornell University.' Correction of conventional techniques for determining CSTR kinetics involved the use of a per unit mass basis for concentrations and kinetics, and modification of the CSTR mass balance to account for the mass removed as biogas. As a result, modified definitions for retention

\footnotetext{
*Current address: CIBA-GEIGY Corp., P.O. Box 18300,
} Greensboro, NC 27419-8300, U.S.A. times and for first order kinetic rate coefficients are presented. Two novel procedures were developed to allow rapid determination of the mass converted to and removed as biogas. A procedure for correcting measured biogas volumes to standard conditions (necessary for determination of mass removals) by compensating for temperature, water vapor content and headspace effects is also shown.

\section{MASS-BASED CALCULATIONS}

The conventional basis for calculating and reporting concentrations and rates is volumetric (i.e., $\mathrm{g}^{-1}$ and $\left.\mathrm{g}(1 \cdot \mathrm{d})^{-1}\right)$. In dilute aqueous systems, the relationship between mass and volume is essentially constant, with a kilogram of liquid occupying approximately one liter of volume. This relationship does not hold true for higher solids reactors where the effective reactor volumes are highly variable, since gas voids may occupy a significant portion of the reactor volume. The net volume occupied varies with the type of substrate, the reactor solids content, the rate of gas production, and the degree of compaction. This variability makes volume a poor basis for calculations. A mass basis is more reliable for research, since the net reactor mass is not affected by transient volume variations. On the mass basis, concentrations and rates 
are calculated and reported on a $\mathrm{g} \mathrm{kg}^{-1}$ and $\mathrm{g}(\mathrm{kg} \cdot \mathrm{d})^{-1}$ basis, respectively.

Use of the mass basis is advantageous for many bench scale reactor configurations, where reactor masses can easily be determined and controlled through the use of accurate, high capacity electronic scales. Conversion from mass-based data to a volumetric basis requires only a measurement or estimate of the wet density (wet mass volume ${ }^{-1}$ ).

\section{STANDARD BIOGAS VOLUMES}

Biogas as produced contains methane, carbon dioxide, water vapor and trace amounts of other gases. From a volumetric standpoint, the trace gases can be regarded as negligible. Conversion of as-measured volumes to standard conditions (defined in this paper as dry biogas (water vapor excluded) at $0^{\circ} \mathrm{C}$ and one atmosphere of pressure) involves compensating for both volume occupied by water vapor and thermal expansion effects. Typically, volumes are measured at one atmosphere so that no pressure correction is required.
The procedure described here was developed for reactors that were periodically opened in the course of operation. In order to correct for the presence of air or purge gases introduced into the reactor head space by such periodic openings, methane and carbon dioxide contents were normalized to total $100 \%$ of measured gas production. (In cases where head space effects are negligible, the exclusion of water vapor volume can be carried out simply by applying non-normalized methane and carbon dioxide contents to the measured volume and correcting for expansion with Charles' law.)

To correct for the volume occupied by water vapor, biogas can be assumed to be saturated with water vapor if biogas is collected and measured at a temperature equal to or lower than the reactor temperature. It is also assumed that there is no significant solute reduction of water's vapor pressure. Table 1 shows standard steam saturated volumes ${ }^{5}$ (Column $1, \mathrm{ft}^{3}$ volume (lb mass) ${ }^{-1}$ ) converted to water vapor densities (Column 2). These water vapor densities are converted to fractional water vapor volumes (Column 3) by using the general gas law

Table 1. Correction for water vapor content and thermal expansion in biogas. Assumes biogas saturated with water vapor and no solute reduction of water vapor pressure

\begin{tabular}{|c|c|c|c|c|c|c|}
\hline \multicolumn{2}{|c|}{$\begin{array}{c}\text { Biogas } \\
\text { temperature }\end{array}$} & \multirow{2}{*}{$\begin{array}{c}(1) \\
\text { Saturated } \\
\text { steam } \\
\text { volume } \\
\left(\mathrm{ft}^{3} \mathrm{lb}^{-1}\right)\end{array}$} & \multirow{2}{*}{$\begin{array}{l}(2) \\
\text { Water } \\
\text { vapor } \\
\text { density } \\
\left(\mathrm{g} \mathrm{I}^{-1}\right)\end{array}$} & \multirow{2}{*}{$\begin{array}{c}(3) \\
\text { Water } \\
\text { vapor } \\
\text { volume } \\
\left(11^{-1}\right)\end{array}$} & \multirow{2}{*}{$\begin{array}{c}\text { (4) } \\
\text { Dry } \\
\text { biogas } \\
\text { volume } \\
\left(11^{-1}\right)\end{array}$} & \multirow{2}{*}{$\begin{array}{c}(5) \\
\text { Dry } \\
\text { biogas } \\
\text { factor } \\
\left(1 @ 0^{\circ} \mathrm{C}^{-1}\right)\end{array}$} \\
\hline $\mathrm{F}$ & ${ }^{\circ} \mathrm{C}$ & & & & & \\
\hline 32 & 0.0 & 3304.7 & 0.0048 & 0.0060 & 0.9940 & 0.9940 \\
\hline 35 & 1.7 & 2948.1 & 0.0054 & 0.0068 & 0.9932 & 0.9872 \\
\hline 40 & 4.4 & 2445.8 & 0.0065 & 0.0083 & 0.9917 & 0.9758 \\
\hline 45 & 7.2 & 2037.8 & 0.0079 & 0.0100 & 0.9900 & 0.9644 \\
\hline 50 & 10.0 & 1704.8 & 0.0094 & 0.0121 & 0.9879 & 0.9530 \\
\hline 55 & 12.8 & 1432.0 & 0.0112 & 0.0146 & 0.9854 & 0.9414 \\
\hline 60 & 15.6 & 1207.6 & 0.0133 & 0.0174 & 0.9826 & 0.9296 \\
\hline 65 & 18.3 & 1022.1 & 0.0157 & 0.0208 & 0.9792 & 0.9176 \\
\hline 70 & 21.1 & 868.4 & 0.0184 & 0.0247 & 0.9753 & 0.9053 \\
\hline 75 & 23.9 & 740.3 & 0.0216 & 0.0293 & 0.9707 & 0.8926 \\
\hline 80 & 26.7 & 633.3 & 0.0253 & 0.0346 & 0.9654 & 0.8795 \\
\hline 85 & 29.4 & 543.6 & 0.0295 & 0.0406 & 0.9594 & 0.8660 \\
\hline 90 & 32.2 & 468.1 & 0.0342 & 0.0476 & 0.9524 & 0.8518 \\
\hline 95 & 35.0 & 404.4 & 0.0396 & 0.0556 & 0.9444 & 0.8371 \\
\hline 100 & 37.8 & 350.4 & 0.0457 & 0.0648 & 0.9352 & 0.8216 \\
\hline 105 & 40.6 & 304.5 & 0.0526 & 0.0752 & 0.9248 & 0.8052 \\
\hline 110 & 43.3 & 265.4 & 0.0604 & 0.0870 & 0.9130 & 0.7879 \\
\hline 115 & 46.1 & 231.9 & 0.0691 & 0.1005 & 0.8995 & 0.7696 \\
\hline 120 & 48.9 & 203.3 & 0.0788 & 0.1156 & 0.8844 & 0.7500 \\
\hline 125 & 51.7 & 178.6 & 0.0897 & 0.1327 & 0.8673 & 0.7292 \\
\hline 130 & 54.4 & 157.3 & 0.1018 & 0.1520 & 0.8480 & 0.7070 \\
\hline 131 & 55.0 & 153.4 & 0.1044 & 0.1561 & 0.8439 & 0.7024 \\
\hline 135 & 57.2 & 138.9 & 0.1153 & 0.1736 & 0.8265 & 0.6832 \\
\hline 140 & 60.0 & 123.0 & 0.1302 & 0.1977 & 0.8023 & 0.6578 \\
\hline 145 & 62.8 & 109.1 & 0.1468 & 0.2246 & 0.7753 & 0.6304 \\
\hline 150 & 65.6 & 97.1 & 0.1650 & 0.2547 & 0.7453 & 0.6010 \\
\hline
\end{tabular}

Regression for factors at temperatures of 15 to $27^{\circ} \mathrm{C}$ :

Water vapor density (Col. 2) $\left.=0.005396 \mathrm{e}^{(0.058080} \mathrm{TC}\right)$

Dry biogas factor $(\mathrm{Col} .5)=1.00-0.0045 \times T^{\circ} \mathrm{C}$. 
$(P V=n R T)$ solved for volume at constant pressure of 1 atmosphere. Subtracting these values from unity yields the dry (non-water) gas fraction (Column 4) at the measured temperature. Charles' Law, which states that gas volumes vary inversely with absolute temperature, was applied to these fractions in order to correct volumes to $0^{\circ} \mathrm{C}$. The resulting "dry biogas factor" (Column 5) thus corrects for both temperature and water vapor effects. Multiplying the measured biogas volume at given temperature, $V_{\mathrm{t}}$, by the dry biogas factor for that temperature yields $V_{0}$, the standard volume of dry biogas at $0^{\circ} \mathrm{C}$.

$$
V_{0}=D B F_{1} \times V_{\mathrm{l}}
$$

where

$$
\begin{aligned}
V_{0}= & \text { dry (non-water) biogas volume at } \\
& 0^{\circ} \mathrm{C} \text { (1) }
\end{aligned}
$$

$D B F_{1}=$ dry biogas factor $\left(1\right.$ dry at $0^{\circ} \mathrm{C}$ (1 measured at $\left.T^{\circ} C\right)^{-1}$ )

$V_{\mathrm{t}}=$ biogas volume measured at temperature $T$ (1).

To simplify application, a temperature vs. dry biogas factor regression was performed. The linear regression $(R=0.9997)$ covers a range of common ambient temperatures $\left(15^{\circ}\right.$ to $\left.27^{\circ} \mathrm{C}\right)$ :

$$
D B F_{1}=1-0.0045 \times T
$$

where

$$
\begin{aligned}
T= & \text { biogas temperature }\left({ }^{\circ} \mathrm{C}\right) \text {, within the } \\
& \text { range } 15^{\circ} \text { to } 27^{\circ} \mathrm{C} \text {. }
\end{aligned}
$$

\section{DETERMINATION OF MASS REMOVALS}

The mass removal rate is here defined as the rate at which substrate volatile solids and water (consumed during hydrolysis) are converted to and removed as biogas. Two novel procedures are presented for calculating mass removals. The first, termed the mass loss basis, is based on direct measurement of the change in total reactor mass and is suitable only for smaller-scale experimental systems. The second procedure, termed the biogas basis, calculates the mass removed from the volume and composition of biogas produced.

\subsection{Reactor mass loss basis}

In a closed reactor system in which the only continuous mass flow is that of biogas leaving the reactor (i.e. batch or periodically-fed systems), direct measurements of reactor mass over time can be used to quantify removals. The reactor mass loss can be assumed to equal the mass of dry biogas removed if the loss of water vapor in the biogas is compensated for. The mass loss due to evaporation is calculated from the biogas volume:

$$
W=V_{\mathrm{t}} \times D w
$$

where

$$
\begin{aligned}
W= & \text { mass of water lost by evaporation in } \\
& \text { biogas }(\mathrm{g}) \\
V_{\mathrm{t}}= & \text { biogas volume at ambient temperature } \\
& (\mathrm{l}) \\
D w= & \text { water vapor density ( } \mathrm{g} \text { water ( } 1 \text { bio- } \\
& {\text { gas } \left.)^{-1}\right) .}
\end{aligned}
$$

Water vapor densities are listed in Table 1 (Column 2). The temperature/vapor density relationship is exponential, and an exponential regression was performed to simplify application. The regression covers a range of common ambient temperatures $\left(15^{\circ} \mathrm{C}\right.$ to $\left.27^{\circ} \mathrm{C}\right)$ :

$$
D w=0.005396 \mathrm{e}^{(0.05808 T)}
$$

where

$$
\begin{aligned}
D w= & \text { water vapor density }(\mathrm{g} \text { water }(1 \text { bio- } \\
& \text { gas } \left.)^{-1}\right) \\
T= & \text { ambient biogas temperature }\left({ }^{\circ} \mathrm{C}\right) .
\end{aligned}
$$

The corrected mass loss is then defined as:

$$
M R_{\mathrm{m}}=I-F-W
$$

where

$$
\begin{aligned}
M R_{\mathrm{m}}= & \text { mass removed }(\mathrm{g}) \text { during interval (mass } \\
& \text { loss method) } \\
I= & \text { initial reactor mass (beginning of inter- } \\
& \text { val) } \\
F= & \text { final reactor mass (end of interval) } \\
W= & \text { mass of water lost by evaporation in } \\
& \text { biogas. }
\end{aligned}
$$

The mass removal rate $\left(M R R_{\mathrm{m}}, \mathrm{g}(\mathrm{kg} \cdot \mathrm{d})^{-1}\right)$ is then defined as $M R_{\mathrm{m}}$ divided by the net reactor mass $(\mathrm{kg})$ and length of the time interval (days).

\subsection{Biogas basis}

The biogas-based method of determining removals calculates the mass of dry biogas produced. Dry biogas is assumed to behave as an ideal gas, and is assumed to consist entirely of carbon dioxide and methane (normalized to negate reactor head space effects). The biogas mass is calculated using the molecular weights of methane and carbon dioxide (16 and 
$44 \mathrm{~g} \mathrm{~mol}^{-1}$, respectively), and the molar volume of an ideal gas at STP $\left(22.4131 \mathrm{~mol}^{-1}\right)$ :

$B=V_{0} \times \frac{\left(16 \times \mathrm{CH}_{4} / 100\right)+\left(44 \times \mathrm{CO}_{2} / 100\right)}{22.413}$

where

$$
\begin{aligned}
B= & \text { biogas mass }(\mathrm{g}) \\
V_{0}= & \text { dry biogas volume at STP (l) } \\
\mathrm{CH}_{4}= & \text { biogas normalized methane content } \\
& \text { (volume percent) } \\
\mathrm{CO}_{2}= & \text { biogas normalized carbon dioxide con- } \\
& \text { tent (volume percent) }
\end{aligned}
$$

Substituting the relationship for normalized biogas $\left(\mathrm{CO}_{2}=100-\mathrm{CH}_{4}\right)$ into eqn. 6 , and simplifying constants results in:

$$
M R_{\mathrm{b}}=B=V_{0}\left(1.963-\left(0.01249 \times \mathrm{CH}_{4}\right)\right)
$$

where

$$
\begin{aligned}
M R_{\mathrm{b}}= & \text { mass removed }(\mathrm{g}) \text { (biogas method) } \\
V_{0}= & \text { dry biogas volume STP }(\mathrm{l}) \\
\mathrm{CH}_{4}= & \text { biogas normalized methane content } \\
& \text { (volume percent) }
\end{aligned}
$$

The mass removal rate $\left(M R R_{\mathrm{b}}, \mathrm{g}(\mathrm{kg} \cdot \mathrm{d})^{-1}\right)$ is then defined as $M R_{\mathrm{b}}$ divided by the net reactor mass $(\mathrm{kg})$ and the time interval (days).

Conservation of mass dictates that these two largely independent procedures should yield equal results $\left(M R R_{\mathrm{m}}=M R R_{\mathrm{b}}\right)$, thus providing a cross-check of the validity of data. Divergence in results between the two techniques often indicates gas leakage, which might otherwise go undetected. Table 2 shows good agreement between mass removal rates determined by both techniques for a series of steady performance conditions for semi-continuously fed-and-mixed (SCFM) slurry digesters. ${ }^{6}$

\section{DETERMINATION OF HYDROLYTIC WATER CONSUMPTION}

Methane fermentation of most substrates involves hydrolysis, with water often contributing substantially to the mass removed as biogas. The mass of biogas removed thus includes both converted substrate mass and water consumed during substrate hydrolysis. For example, the net stoichiometry of biogas produced from a hexose polymer (i.e. starch or cellulose) with $n$ hexose units shows that $10 \%$ of the mass of biogas produced originates as water:

$$
\begin{aligned}
& \left(\mathrm{C}_{6} \mathrm{H}_{10} \mathrm{O}_{5}\right)_{n}+n \mathrm{H}, \mathrm{O} \quad \rightarrow 3 n \mathrm{CO}_{2}+3 n \mathrm{CH}_{4} \\
& \begin{array}{c}
\text { Molecular weights: } \\
162 n
\end{array} \\
& \text { SUBSTRATE MASS + WATER MASS } \rightarrow \text { BIOGAS MASS } \\
& \text { CONVERTED CONSUMED PRODUCED }
\end{aligned}
$$

A hydrolysis factor $(H)$ can be defined as the fraction of biogas mass that originated as water hydrolytically consumed. In the above example, $H$ is $18 / 180$, which equals $0.1 \mathrm{~g}$ water ( $\mathrm{g}$ biogas produced $)^{-1}$.

One method for determining $H$ is empirical, which assumes that the difference between steady-state volatile solids (VS) removals and mass removals is hydrolytically-consumed water. The VS removal rate ( $V S R R$, as calculated from VS balance) represents the substrate mass converted. This, in conjunction with the mass removal rate ( $M R R$, from eqn. (5) and/or (7)), allows determination of $H$ :

$$
H=1-(V S R R / M R R)
$$

where

$H=$ hydrolysis factor, $\mathrm{g}$ water consumed (g mass removed) ${ }^{-1}$

$V S R R=$ VS removal rate, $\mathrm{g}$ VS $(\mathrm{kg} \cdot \mathrm{d})^{-1}$

$M R R=$ mass removal rate (mass loss and/or biogas basis), $\mathrm{g}(\mathrm{kg} \cdot \mathrm{d})^{-1}$.

A second method for the determination of $H$, based on the fermentation stoichiometry equation of Buswell et al. ${ }^{7.8}$ can be used if the composition of the substrate biodegradable fraction is known or estimable. It is assumed that ammonia released is retained in solution and is balanced by bicarbonate derived from product carbon dioxide. The equation presented here is thus modified from its original form to retain one mole $\mathrm{CO}_{2}$ in solution per mole $\mathrm{NH}_{3}$ produced (resulting in aqueous $\mathrm{NH}_{4}^{+}$and $\mathrm{HCO}_{3}^{-}$):

$$
\begin{aligned}
\mathrm{C}_{n} & \mathrm{H}_{a} \mathrm{O}_{b} \mathrm{~N}_{c}+[n-0.25 a-0.5 b+1.75 c] \mathrm{H}_{2} \mathrm{O} \\
\rightarrow & {[0.5 n+0.125 a-0.25 b-0.375 c] \mathrm{CH}_{4} } \\
& +[0.5 n-0.125 a+0.25 b-0.625 c] \mathrm{CO}_{2} \\
& +c \mathrm{NH}_{4}^{+}+c \mathrm{HCO}_{3}^{-} .
\end{aligned}
$$


Table 2. Comparison of mass-loss based $\left(M R R_{\mathrm{m}}\right)$ and biogas-based $\left(M R R_{\mathrm{b}}\right)$ removal rates: steady performance operation of SCFM digesters ${ }^{6}$

\begin{tabular}{|c|c|c|c|c|c|c|}
\hline \multirow[b]{2}{*}{ Substrate } & \multirow[b]{2}{*}{$\begin{array}{l}\text { Temp. } \\
\left({ }^{\circ} \mathrm{C}\right)\end{array}$} & \multirow[b]{2}{*}{$\begin{array}{c}\text { VS } \\
\text { loading } \\
\text { rate } \\
\left(\mathbf{g}(\mathbf{k g} \cdot \mathrm{d})^{-1}\right)\end{array}$} & \multirow[b]{2}{*}{$\begin{array}{c}\text { Gas } \\
\text { production } \\
\text { rate }^{*} \\
\left(1(\mathrm{~kg} \cdot \mathrm{d})^{-1}\right)\end{array}$} & \multirow[b]{2}{*}{$\begin{array}{c}\text { Biogas } \\
\text { methane } \\
\text { content } \\
(\%)\end{array}$} & \multicolumn{2}{|c|}{ Mass removal rate } \\
\hline & & & & & $\begin{array}{l}\text { Mass } \\
\text { basis } \\
\quad(\mathrm{g}(\mathrm{kg})\end{array}$ & $\begin{array}{l}\text { Biogas } \\
\text { basis } \\
\left.1^{-1}\right)\end{array}$ \\
\hline Sorghum & 55 & 1.21 & 0.84 & 55.5 & 1.08 & 1.07 \\
\hline Sorghum & 55 & 3.37 & 2.15 & 52.3 & 2.75 & 2.81 \\
\hline Sorghum & 55 & 2.44 & 1.55 & 53.6 & 2.08 & 2.00 \\
\hline Sorghum & 35 & 1.34 & 0.67 & 53.0 & 0.86 & 0.82 \\
\hline Sorghum & 25 & 0.20 & 0.14 & 52.6 & 0.18 & 0.18 \\
\hline Sorghum & 25 & 0.50 & 0.28 & 51.7 & 0.38 & 0.36 \\
\hline Sorghum & 55 & 3.99 & 2.29 & 52.8 & 3.04 & 2.99 \\
\hline Sorghum & 55 & 5.03 & 2.89 & 51.9 & 3.44 & 3.80 \\
\hline Sorghum & 55 & 3.36 & 2.12 & 55.1 & 2.72 & 2.69 \\
\hline Sorghum & 55 & 2.91 & 1.60 & 55.1 & 2.06 & 2.04 \\
\hline Napiergrass & 55 & 3.95 & 1.82 & 53.0 & 2.42 & 2.37 \\
\hline Napiergrass & 55 & 2.02 & 1.01 & 54.4 & 1.31 & 1.30 \\
\hline Napiergrass & 55 & 2.01 & 1.02 & 56.0 & 1.26 & 1.29 \\
\hline Napiergrass & 55 & 2.72 & 1.59 & 60.5 & 2.02 & 1.92 \\
\hline Napiergrass & 35 & 2.61 & 1.10 & 51.9 & 1.39 & 1.37 \\
\hline Napiergrass & 35 & 1.40 & 0.63 & 49.8 & 0.79 & 0.80 \\
\hline Napiergrass & 35 & 1.99 & 0.77 & 50.6 & 0.97 & 0.96 \\
\hline Napiergrass & 25 & 0.50 & 0.21 & 52.6 & 0.30 & 0.27 \\
\hline Wheat Straw & 55 & 3.50 & 1.36 & 54.6 & 1.80 & 1.74 \\
\hline Wheat Straw & 25 & 1.50 & 0.43 & 54.2 & 0.51 & 0.55 \\
\hline Cattail & 55 & 2.03 & 0.66 & 52.1 & 0.98 & 0.86 \\
\hline
\end{tabular}

*Reported as dry biogas at $0^{\circ} \mathrm{C}$.

The coefficients generated by eqn. (10) are used to determine $H$. For the general case of $c$ moles $\mathrm{N}, x$ moles $\mathrm{H}_{2} \mathrm{O}$ consumed, $y$ moles $\mathrm{CH}_{4}$ and $z$ moles $\mathrm{CO}_{2}$ produced (assuming that water contributes one mole $\mathrm{H}^{+}$for deamination of $\mathrm{NH}_{2}$ per mole $\mathrm{N}$ ):

$$
H=(18(x-c)-c) /(16 y+44 z) .
$$

Simplifying and expressing in terms of the Buswell equation variables gives:

$$
\begin{aligned}
& H=(18 n-4.5 a-9 b+12.5 c) / \\
&(30 n-3.5 a+7 b-33.5 c) .
\end{aligned}
$$

The use of the equation is most appropriate where feed composition, particularly the biodegradable fraction, is well-defined. For more complex feeds, estimation may be possible if fiber composition is known. Table 3 shows excellent agreement between hydrolysis factors measured from six steady performance digesters ${ }^{9}$ using sorghum or mixed sorghum/cellulose feedstocks and the $H$ factor determined from eqn (12) using estimated composition.

\section{RETENTION TIME}

The hydraulic retention time $(H R T)$, the theoretical average residence time of a volume of liquid in a completely-mixed reactor, is conventionally defined as the reactor volume $(V)$ divided by the rate of liquid throughput $(Q$, volume time $\left.{ }^{-1}\right)^{10}$. Inherent in the use of $Q$ as throughput is the assumption that the rate of mass inflow equals the rate of mass outflow,

Table 3. Comparison of estimated $\boldsymbol{H}$ with $\boldsymbol{H}$ determined from six digesters fed sorghum or 1:1 sorghum/cellulose mix

\begin{tabular}{lcc}
\hline Substrate & $\begin{array}{c}\text { VS loading rate } \\
\left(\mathrm{g}(\mathrm{kg} \cdot \mathrm{d})^{-1}\right)\end{array}$ & $\begin{array}{c}H \\
\left(\mathrm{~g} \mathrm{H}_{2} \mathrm{O}(\mathrm{g} \text { mass removed })^{-1}\right)\end{array}$ \\
\hline Sorghum & 4 & 0.109 \\
Sorghum/Cellulose & 8 & 0.121 \\
Sorghum & 8 & 0.122 \\
Sorghum & 12 & 0.090 \\
Sorghum/Cellulose & 18 & 0.105 \\
Sorghum/Cellulose & 24 & 0.102 \\
& Mean & 0.108 \\
& Standard deviation & 0.011 \\
$H$ predicted from substrate composition & 0.11 \\
Sorghum & & 0.11 \\
Sorghum/Cellulose & & \\
\hline
\end{tabular}


which is technically incorrect since the mass removed as biogas is ignored. To illustrate, Fig. 1 shows a CSTR mass balance that incorporates biogas mass losses. A reactor of net mass $M$ is loaded at rate $Q o$ (mass time ${ }^{-1}$ ), resulting in mass removal rate MRR and effluent rate $Q e$ (mass time ${ }^{-1}$ ). In dilute systems, ignoring biogas removals is of little consequence since the mass loss is negligible when compared to other mass flows. However, in higher solids reactors the difference between inflow and outflow may be significant.

The difference between inflow $(Q 0)$ and outflow $(Q e)$ raises the question of which flow the retention time should be based on. The actual residence time of liquids in the reactor is defined by the outflow ${ }^{11}(M / Q e)$, which in CSTR systems is equivalent to the solids retention time $(S R T)$, also referred to as the mean cell residence time:

$$
H R T_{\text {actual }}=M / Q e=M X / Q e X=S R T
$$

where

$$
\begin{aligned}
& X=\text { microbial VS concentration in reactor } \\
& \text { and effluent. }
\end{aligned}
$$

Conversely, the retention time based on the inflow $\left(M / Q o\right.$, here symbolized as $\left.H R T_{\mathrm{i}}\right)$ is not the actual retention time. However, $H R T_{\mathrm{i}}$ is still of utility in defining loading conditions, since $Q o$ is an independent control variable. In systems with high rates of biogas production, $Q e$ can be significantly less than $Q o$, resulting in retention times that are much longer than $H R T_{\mathrm{i}}$ :

$$
S R T=M / Q e>M / Q o=H R T_{\mathrm{i}} .
$$

The ratios $Q o / Q e$ and $S R T / H R T_{\mathrm{i}}$ increase with the extent of substrate conversion. $S R T / H R T_{\mathrm{i}}$ ratios approaching 2 are possible in high solids reactors fed highly biodegradable substrates.

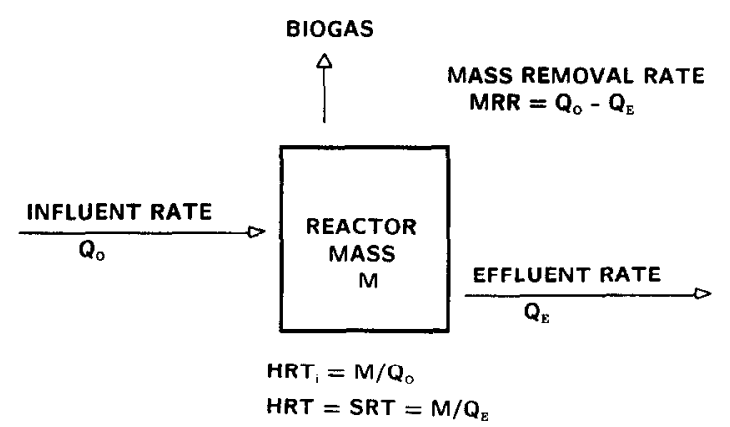

Fig. 1. Mass balance of a steady-state continuously fed-andmixed reactor.

\section{MODIFIED FIRST ORDER CSTR REACTION KINETICS}

Quantitation of biogas mass losses allows modification of kinetic mass balance equations, such as the first order model. First-order substrate utilization kinetics, while lacking the capacity of more complex models for predicting performance at short retention time or dynamic conditions,${ }^{12}$ provide a simple means for describing stable performance under practical operating conditions. For CSTR systems, the biodegradable substrate mass balance equation appears as: $:^{13.14}$

\section{CHANGE IN SUBSTRATE MASS}

$$
\begin{aligned}
= & \text { INFLUENT SUBSTRATE MASS } \\
& \text { - } \\
\text { - } & \text { SUFLUSTRAT SUBSTRATE MASS } \\
& \text { REMOVED IN BIOGAS. }
\end{aligned}
$$

For conventional (dilute) applications, this balance is developed on a volumetric basis using $Q$ to represent throughput, ${ }^{10}$ which neglects the mass removed as biogas. The following balance, developed on a mass basis, accounts for biogas mass losses by distinguishing $Q o$ and $Q e$ :

$$
M \mathrm{~d} S / \mathrm{d} t=Q o S o-Q e S e-k M S e
$$

where

$$
\begin{aligned}
M= & \text { reactor wet mass } \\
\mathrm{d} S / \mathrm{d} t= & \text { rate of change of substrate concen- } \\
& \text { tration, mass mass }{ }^{-1} \text { time }^{-1} \\
Q o= & \text { rate of inflow, wet mass time }{ }^{-1} \\
Q e= & \text { rate of outflow, wet mass time } \\
S o= & \text { influent substrate concentration, sub- } \\
& \text { strate mass (wet mass) })^{-1} \\
S e= & \text { effluent substrate concentration, sub- } \\
& \text { strate mass (wet mass) })^{-1} \\
k= & \text { first order rate coefficient, time }{ }^{-1}
\end{aligned}
$$

By definition, $\mathrm{d} S / \mathrm{d} t$ at steady state equals zero, thus

$$
Q o S o-Q e S e-k M S e=0 .
$$

A constant reactor mass requires that inflow equal outflow plus biogas mass removals (the VS removal rate $(k M S e)$ divided by the $(1-H)$ term yields the mass removal rate):

$$
Q o=Q e+k M S e /(1-H)
$$

where

$$
\begin{aligned}
H= & \text { substrate hydrolysis factor, mass water } \\
& \text { consumed (mass loss) })^{-1} .
\end{aligned}
$$


Substituting this relationship for $Q o$ and the definition of $S R T(M / Q e)$ into eqn. (17) and solving for $k$ yields

$k=(S o-S e) /\left(S e S R T\left(1-\frac{S o}{(1-H)}\right)\right)$

(This differs from the conventional definition by the $(1-S o /(1-H))$ term. Note that for dilute aqueous systems the additional term approaches unity, which indicates that the equation will yield results similar to the conventional form in that case.) If derived on the basis of $H R T_{\mathrm{i}}$, the equation becomes

$$
k=(S o-S e) /\left(S e H R T_{i}\left(1-\frac{S e}{(1-H)}\right)\right) .
$$

Substrate concentrations $S o$ and $S e$ are easily calculable from biodegradable VS (BVS) loading and removal rates:

$$
\begin{aligned}
& S o=B L R /\left(1000 / H R T_{\mathrm{i}}\right) \\
& S e=(B L R-R R) /\left(\left(1000 / H R T_{\mathrm{i}}\right)-M R R\right)
\end{aligned}
$$

where

$$
\begin{aligned}
B L R & =\text { BVS loading rate, } \mathrm{g} \mathrm{BVS}(\mathrm{kg} \cdot \mathrm{d})^{-1} \\
R R & =\text { VS removal rate, } \mathrm{g} \mathrm{VS}(\mathrm{kg} \cdot \mathrm{d})^{-1} \\
M R R & =\text { mass removal rate, } \mathrm{g}(\mathrm{kg} \cdot \mathrm{d})^{-1}
\end{aligned}
$$

\section{DISCUSSION}

These procedures were developed for the analysis and modeling of high rate, high solids methane fermentation digesters. Some procedures (particularly those for gas standardization and mass removal rate determinations) may be employed with other types of digesters as well. Some implications and suggestions for application follow.

\subsection{Gas volume standardization}

Biogas production data is most useful if reported at standardized conditions, or, at the least, reported with conditions of measurement. Unfortunately, published reports do not always state if or how data have been standardized, limiting the reader's ability to interpret and compare data. The potential for error in interpreting non-standardized data is substantial: one liter of saturated (wet) biogas as measured at $35^{\circ} \mathrm{C}$ contains only 0.831 of dry (non-water) gas at $0^{\circ} \mathrm{C}$. If measured at $55^{\circ} \mathrm{C}$ the error is even greater: one liter of saturated biogas contains only 0.71 of dry gas at $0^{\circ} \mathrm{C}$. While the standard conditions presented here (dry biogas at $0^{\circ} \mathrm{C}$ ) are not promulgated as a universal standard, they are required for the application of the biogas-based mass removal procedures in this article.

\subsection{Mass removal rates}

The novel methods presented for the determination of mass removal rates have several significant applications. First, determination of the mass removal rate from biogas production data provides a rapid means of assessing digester kinetics. If the substrate hydrolysis factor $(H)$ is known or estimable, the rate and efficiency of VS conversion can be estimated directly from biogas production. This is, for example, several days faster than VS balances based on influent and effluent solids analyses.

Second, the use of the largely independent mass removal determinations allows crosschecking of gas production and removal data. In experimental systems where reactor mass losses can be directly measured, the two mass removal techniques (mass loss-basis and biogasbasis) allow for rapid checking for biogas leaks. (Technically, the mass loss method is dependent on measured biogas volumes in order to correct for the mass of water vapor removed. However, this is negligible in view of the wide divergence in the results of the two methods when a biogas leak occurs.) To cross-check gas production in cases where reactor mass losses cannot be measured, VS conversion rates (as determined by VS mass balances) in combination with a known or estimated substrate hydrolysis factor $(H)$ can be used to calculate a mass removal rate. This can then be compared to the biogas-based mass removal rate. However applied, the ability to correlate and cross-check gas production. mass removals and VS removals is a powerful research tool.

Third, determination of the mass removal rate allows correction of the CSTR mass balance for biogas mass removals. The implications of this are discussed below.

\subsection{CSTR mass balance and retention times}

Modification of the mass balance equation for high solids/high rate CSTR systems is necessary since the mass lost as biogas, ignored in the conventional mass balance as a negligible term, is a significant mass flow. In a $10 \%$ TS 
sorghum-fed slurry digester, the biogas mass loss comprised over $21 \%$ of the wet mass loaded. ${ }^{6}$ In two high solids digesters, the mass removed as biogas represented 42 to $44 \%$ of the total wet mass loaded. ${ }^{15}$

In the above cases, the effluent mass flow rate $(Q e)$ was $58 \%$ (high solids digester) to $79 \%$ (slurry digester) of the inflow rate $(Q o)$. Because of this, the difference between the conventional influent-based $H R T_{\mathrm{i}}$ and the true retention time ( $S R T$, equal to outflowbased $H R T$ ) was substantial. The $S R T / H R T_{\mathrm{i}}$ ratio was almost 1.3 for a $10 \%$ TS slurry digester, ${ }^{6}$ and ratios approaching 2 have been observed in high solids systems. ${ }^{15}$ As mentioned before, while the inflow-based $H R T_{\mathrm{i}}$ does not define the actual retention time, it may still be of use since it describes the total mass loading rate. It also describes the retention time that would result if no removals occurred.

\subsection{First order kinetics}

As shown with the first-order model (chosen because it provides a simple basis for comparing stable performance under practical conditions), accounting for biogas mass removals requires modification of conventional mass balance equations. Modifications to the conventional first-order definition also included the use of a mass rather than volumetric basis. For dilute systems with low gas production rates the additional $(1-S o /(1-H))$ term (eqn. 19) approaches unity, yielding results similar to the conventional form. For higher solids systems the effect is more significant. For the $10 \%$ TS slurry system, the modified balance increased $k$ by about $5 \%$. For high solids systems, ${ }^{15} k$ may be raised by 7 to $10 \%$.

The reaction rate coefficient definition presented here was based on biodegradable vS concentrations ( $S o$ and $S e$ ), rather than simply on total VS present. This enables comparison of rate coefficients between substrates with differing biodegradabilities.

\section{EXAMPLE CALCULATION}

This example is based on data from a semicontinuously fed-and-mixed reactor operated at thermophilic conditions. ${ }^{6}$ The reactor, operated at $10.5 \% \mathrm{TS}$, was fed dried sorghum and water twice weekly. The reactor net mass (after feeding) was maintained at $5.00 \mathrm{~kg}$. Numbers in brackets refer to equations.
Totals for 35 days of steady performance operation:

Wet mass loaded: $1666.5 \mathrm{~g}$

VS loaded: $426.7 \mathrm{~g}$

Organic loading rate: $2.44 \mathrm{~g}(\mathrm{~kg} \cdot \mathrm{d})^{-1}$

Biodegradability: 0.91 gBVS (gVS) ${ }^{-1}$

Cumulative feeding interval mass losses: $368.6 \mathrm{~g}$

Biogas ambient temp: $20^{\circ} \mathrm{C}$

Biogas volume measured: 297.41

Biogas methane content: $53.6 \%$.

Biogas volumes

Dry biogas factor for $20^{\circ} \mathrm{C}$ [2]

$=1-0.0045(20)=0.910$

Dry biogas volume at STP [1]

$=0.910 \times 297.4=270.61$.

\section{Removals}

Mass loss basis:

Water vapor density factor [4]

$=D w=0.005396 \exp (0.05808 \times 20)$

$=0.0172 \mathrm{~g} \mathrm{l}^{-1}$

Evaporative mass losses [3] $=0.0172 \times 297.4=5.1 \mathrm{~g}$

Corrected mass loss [5] $=368.6-5.1=363.5 \mathrm{~g}$ removed

Mass removal rate $=363.5 /(5 \times 35)$

$$
=2.08 \mathrm{~g}(\mathrm{~kg} \cdot \mathrm{d})^{-1}
$$

Biogas basis:

Mass removed [7]

$$
=270.6(1.963-0.01249 \times 53.6)=350.0 \mathrm{~g}
$$

Mass removal rate $=350.0 /(5 \times 35)$

$$
=2.00 \mathrm{~g}(\mathrm{~kg} \cdot \mathrm{d})^{-1}
$$

Average mass removal rate (both methods) $=2.04 \mathrm{~g}(\mathrm{~kg} \cdot \mathrm{d})^{-1}$.

\section{Retention times}

$H R T_{\mathrm{i}}$ (influent basis) [14]

$=5000 /(1666.5 / 35)=105$ days

$S R T[13]=5000 /((1666.5-357.4) / 35)$

$=134$ days

$S R T / H R T_{\mathrm{i}}$ ratio $=1.28$.

Reaction rate coefficient ( $H$ and $V S R R$ estimated from more recent data)

$$
\begin{aligned}
\text { So }[21]= & (2.44 \times 0.91) /(1000 / 105) \\
= & 0.233 \\
\text { Se }[22]= & ((2.44 \times 0.91-1.84) / \\
& ((1000 / 105)-2.04)) \\
= & 0.0508 \\
k[20]= & (0.233-0.0508) /(0.0508 \times 105 \\
& \times(1-(0.0508 /(1-0.1)))) \\
= & 0.036 \text { day }^{-1} .
\end{aligned}
$$


Acknowledgements-These procedures were developed during research carried out at Cornell University supported by the Gas Research Institute and the New York State Energy Research and Development Authority under GRI Contract No. 5083-226-0848, Drs H. Ron Isaacson and Thomas D. Hayes, technical managers. The authors thank F. G. Herndon and D. J. Rector for their contributions.

\section{REFERENCES}

1. W. J. Jewell, H. Kang, F. G. Herndon, B. K. Richards and T. E. White, Engineering Design Considerations for Methane Fermentation of Energy Crops. Cornell University 4th Year Annual Report for the Gas Research Institute. GRI Report No. 88/0263. Chicago, Illinois, 60631 (1987).

2. D. E. Jerger and D. P. Chynoweth, Anaerobic digestion of sorghum biomass. Biomass 147, 99-113 (1987).

3. W. J. Wujick and W. J. Jewell, Dry anaerobic fermentation. Biotechnol. Bioeng. Symp. 10, 43-65 (1980).

4. L. De Baere, O. Verdonck and W. Verstraete, High rate dry anaerobic composting process for the organic fraction of solid wastes. Biotechnol. Bioeng. Symp. 15, 321-330 (1985).

5. R. C. Weast (Ed.) Handbook of Chemistry and Physics, 64th Edn. CRC Press, Boca Raton, FL (1984).

6. W. J. Jewell, R. J. Cummings, A. M. Whitney, F. G. Herndon and B. K. Richards, Engineering Design Considerations for Methane Fermentation of Energy Crops. Cornell University 3rd Year Annual Report for the Gas
Research Institute, GRI Report No. 87/0061. Chicago, Illinois. 60631 (1987).

7. A. M. Buswell and M. F. Mueller, Mechanisms of methane fermentation. Ind. Eng. Chem. 44, 550 (1952).

8. G. F. Parkin and W. F. Owen, Fundamentals of anaerobic digestion of wastewater sludges. $A S C E$ JEED 112(5), 867-920 (1980).

9. W. J. Jewell, R. J. Cummings, B. K. Richards and F. G. Herndon, Engineering Design Considerations for Methane Fermentation of Energy Crops-Fundamental Investigations. Cornell University 1st (1988, GRI No. $91 / 0010)$ and 2 nd (1989, in preparation) Year Annual Report for the Gas Research Institute, Chicago, Illinois 60631 .

10. B. J. Clark and M. A. Ungersma (Eds), Wastewater Engineering. McGraw-Hill, New York (1972).

11. R. C. Loehr, Pollution Control for Agriculture. Academic Press, New York, (1977).

12. R. S. Billington, A review of the mathematical modelling of anaerobic digestion with particular reference to hydrolysis. Div. Note DN1305, Nat'l Inst. Agr. Eng. Silsoe, UK. (unpublished) (1985).

13. G. R. Morris, Anaerobic Fermentation of Animal Wastes: A Kinetic and Empirical Design Evaluation. Master's Dissertation, Cornell University (1976).

14. W. J. Jewell and P. L. McCarty, Aerobic decomposition of algae. Env. Sci. Tech. 5 (10), 1023-1031 (1971).

15. B. K. Richards. R. J. Cummings. W. J. Jewell and F. G. Herndon, High solids anaerobic methane fermentation of sorghum and cellulose. Biomass and Bioenergy 1, $47-53(1991)$ 